\title{
Role of Water Vapor Content in the Effects of Aerosol on the Electrification of Thunderstorms: A Numerical Study
}

\author{
Pengguo Zhao ${ }^{1, *}$, Yan Yin ${ }^{2}$, Hui Xiao ${ }^{3}$, Yunjun Zhou ${ }^{1,4}$ and Jia Liu ${ }^{5,6}$ \\ 1 Plateau Atmosphere and Environment Key Laboratory of Sichuan Province, College of Atmospheric Science, \\ Chengdu University of Information Technology, Chengdu 610225, China; zhouyj@cuit.edu.cn \\ 2 Key Laboratory for Aerosol-Cloud-Precipitation of China Meteorological Administration, \\ Nanjing University of Information Science \& Technology, Nanjing 210044, China; yinyan@nuist.ecu.com \\ 3 Institute of Tropical and Marine Meteorology, CMA, Guangzhou 510080,China; xh_8646@163.com \\ 4 Collaborative Innovation Center on Forecast and Evaluation of Meteorological Disasters, \\ Nanjing University of Information Science \& Technology, Nanjing 210044, China \\ 5 Heavy Rain and Drought-Flood Disasters in Plateau and Basin Key Laboratory of Sichuan Province, \\ Chengdu 610072, China; liujia851229@163.com \\ 6 Climate Center of Sichuan Province, Chengdu 610072, China \\ * Correspondence: zpg0402@163.com or zpg@cuit.edu.cn; Tel.: +86-28-8596-6389
}

Academic Editor: Robert W. Talbot

Received: 4 September 2016; Accepted: 16 October 2016; Published: 20 October 2016

\begin{abstract}
We explored the role of the water vapor content below the freezing level in the response of idealized supercell storm electrical processes to increased concentrations of cloud condensation nuclei $(\mathrm{CCN})$. Using the Weather Research and Forecasting model coupled with parameterizations electrification and discharging, we performed 30 simulations by varying both the $\mathrm{CCN}$ concentration and water vapor content below the freezing level. The sensitivity simulations showed a distinct response to increased concentrations of $\mathrm{CCN}$, depending on the water vapor content below the freezing level. Enhancing CCN concentrations increased electrification processes of thunderstorms and produced a new negative charge region above the main positive charge center when there were ample amounts of water vapor below the freezing level. Conversely, there were weak effects on electrification and the charge structure in numerical experiments initialized with lower water vapor content below the freezing level.
\end{abstract}

Keywords: aerosol effects; water vapor content; electrical activity; thunderstorm; WRF model

\section{Introduction}

Previous simulation studies on the effect of aerosol particles on thunderstorm electrification [1-3] have shown that increasing the aerosol concentration leads to the formation of numerous small droplets. These small droplets suppress the collision-coalescence processes and the formation of raindrops. They are then transported above the freezing level, where they enhance the development of ice particles. More ice particles participate in the electrification process under polluted conditions, resulting in an enhancement of this process. Observational studies [4-9] have indicated that anthropogenic aerosol particles produced from metropolitan regions, highways, and factories increase the intensity of thunderstorms, and the density and frequency of lightning. The emission of smoke from forest fires also has a marked impact on the electric processes of thunderstorms, leading to an increase in lightning activity around and downwind of forest regions, an increase in the percentage of positive cloud-to-ground lighting flashes, and a reduction in the percentage of negative cloud-to-ground lighting flashes [10-13]. 
Aerosol particles influence the electrification processes in thunderstorms by influencing liquid water and ice-phase particles. However, the effect of aerosol particles on the microphysical processes and precipitation of convective clouds is different under different environmental conditions. Saleeby et al. [14-16] investigated winter snowfall events over the Park Range of Colorado using Colorado State University's Regional Atmospheric Modeling System. Their results showed that an increase in aerosol particles leads to a reduction in the size of cloud droplets and an increase in the concentration of droplets, although the total amount of precipitation was not changed. Tao et al. [17] showed that the effects of aerosols on convective systems, including their microphysical processes and precipitation, changed under different environmental conditions, by discussing a case of sea breeze convection, a tropical mesoscale convective system, and a mid-latitude squall line. Relative humidity plays a crucial part in the effect of aerosol particles on clouds [18].

Under conditions of low relative humidity, aerosol particles have little impact on the microphysical processes of clouds and the amount of precipitation, whereas they have an obvious impact on clouds under conditions of high relative humidity. Stevens and Feingold [19] showed that clouds can be interpreted as a buffered system in which significant changes in aerosol concentration have little effect on surface precipitation as a result of the complicated dynamic and microphysical processes in clouds. Saleeby et al. [16] showed that the influence of aerosol particles on convective clouds is important under the conditions of high relative humidity and large riming growth, whereas it is unremarkable when the amount of supercooled water is low. To investigate the aerosol effect on clouds under different conditions of low-level water vapor, Carrió and Cotton [20] showed that an increase in aerosol particles increases the content of supercooled water and enhances the growth of riming and ice-phase precipitation under conditions with a high amount of low-level moisture. Increasing aerosol concentration had little impact on microphysical processes and ice-phase precipitation under conditions of a low amount of low-level moisture.

As the concentration of aerosol particles increases, the amount of supercooled water and ice-phase particles may also increase, leading to more ice-phase particles participating in the electrification process and enhancing the intensity of lighting activity during thunderstorms. Under conditions of a high moisture content and obvious riming growth, aerosol particles affect the microphysical processes of the cloud, but show little effect at low moisture content. The purpose of our study is to investigate how the effect of aerosol particles on thunderstorm electrification processes is sensitive to changes in environmental conditions, such as the amount of water vapor. The effect of aerosol particles on electrical activity may be different under different water vapor conditions, because the electrical activity is mainly influenced by ice-phase microphysical processes. To discuss the effect of aerosols on the electrification of thunderstorms at different water vapor content, the Weather Research and Forecasting (WRF) model, coupled with electrification and discharge parameterizations, was used to simulate electrification for different amounts of water vapor below the freezing level and different concentrations of initial cloud condensation nuclei (CCN).

\section{Brief Description of the Model}

There is a general consensus that the main electrification mechanism in thunderstorm is non-inductive. Non-inductive electrification and a simple discharge scheme are coupled in the Morrison two-moment bulk mixed-phase microphysics scheme [21,22] of the WRF (v 3.4.1) model for discussing the effects of vapor condition under the freezing level and different initial CCN concentrations on the electrical development of thunderstorm.

The Morrison microphysics scheme forecasts the mixing ratios and the concentration of cloud droplets, raindrops, ice crystals, snow particles, and graupel particles. Detailed microphysical processes are considered in the Morrison scheme, such as condensation and auto-conversion of cloud droplets; sublimation, deposition, and accretion of ice crystals; and ice multiplication, heterogeneous, and homogeneous freezing of raindrops and cloud droplets. 
Non-inductive electrification is considered in this paper, resulting from rebounding collisions between large and small ice particles. The charge separation rate between large and small ice particles is [23]:

$$
\frac{\partial \rho}{\partial t}=\beta \Delta Q\left(1-E_{x y}\right) E_{x y}^{-1}\left(n_{x a c y}\right)
$$

where $\Delta Q$ is the mean rebounding collision charge separation amount, $E_{x y}$ is the collection efficiency, $n_{x a c y}$ is the collection rate between large and small ice particles, and $\beta$ is the limited coefficient for charge separation rate.

The mean rebounding collision charge separation amount in SP98 scheme is:

$$
\Delta Q=B d^{a} V^{b} \delta q_{ \pm}
$$

where $B, a$, and $b$ are constants [23]; $V$ is the relative fall speed; and $d$ is the diameter of ice crystal or snow particle. The charge amount and polarity of a graupel particle $(\delta q)$ are a function of the rime accretion rate RAR and the critical rime accretion rate $R A R_{C}$, if $R A R>R A R_{C}$, then the graupel are negatively charged, and vice versa.

The electric potential $\Phi$ is computed through solving the Poisson equation:

$$
\nabla^{2} \Phi=-\frac{\rho}{\varepsilon}
$$

The electric permittivity $\varepsilon$ is constant $\left(8.859 \times 10^{-12} \mathrm{~N}^{-1} \cdot \mathrm{m}^{-2} \cdot \mathrm{C}^{2}\right) ; \rho$ is the charge density at the grid point. The electric field $E$ is solved through calculating the electric potential negative difference [24]:

$$
E=-\nabla \Phi
$$

Further details of the microphysical, electrification, and discharge processes in this model have been discussed by Zhao et al. [3].

\section{Experimental Design}

This study conducted idealized three-dimensional (3D) simulations of thunderstorm clouds. The simulation domain was $160 \mathrm{~km} \times 80 \mathrm{~km} \times 20 \mathrm{~km}$, with a horizontal resolution of $0.5 \mathrm{~km}$ and 41 vertical levels. The total simulation time was $60 \mathrm{~min}$ and the time step was $2 \mathrm{~s}$. The initial thermodynamic sounding profile (Figure 1) was based on that of Weisman and Klemp [25] and was used to trigger an ideal continental thunderstorm, which was used as the baseline sounding. A very typical supercell thunderstorm can be simulated by using this thermodynamic sounding profile. Therefore many previous studies [23,26-30] discussed the cloud microphysics, precipitation, and electrical activities of an ideal continental thunderstorm by using the thermodynamic sounding profile used in our paper. These studies prove that the macro- and micro-physical structure and electrical characteristics of a typical continental thunderstorm can be simulated by using this thermodynamic sounding profile. To explore sensitivity tests under different water vapor conditions and initial CCN concentrations, these parameters were varied simultaneously. In this study, we assumed that the aerosol particles consist of ammonium sulfate with $100 \%$ solubility, and serve as CCN to influence the microphysical and electrical processes of a thunderstorm. The concentration of $\mathrm{CCN}$ exponentially decreases with height.

Thirty numerical experiments were conducted by varying the water vapor conditions and CCN concentrations. Figure 2 illustrates the sensitivity experiments conducted in this study. The initial CCN concentration was changed from 300 to $1500 \mathrm{~cm}^{-3}$ at $300 \mathrm{~cm}^{-3}$ intervals to represent changes in the concentration of aerosol particles. The sounding profile of Weisman and Klemp [25] was used to change the vapor mixing ratio $\left(q_{v}\right)$ below the freezing level to represent the variation in the water vapor conditions [20]. The water vapor mixing ratio was decreased to $85 \%$ in intervals of $3 \%$ with 
respect to the baseline sounding (without changing the water vapor content). The water vapor mixing ratios of the sensitivity tests were about $97 \%, 94 \%, 91 \%, 88 \%$, and $85 \%$ of the baseline sounding.

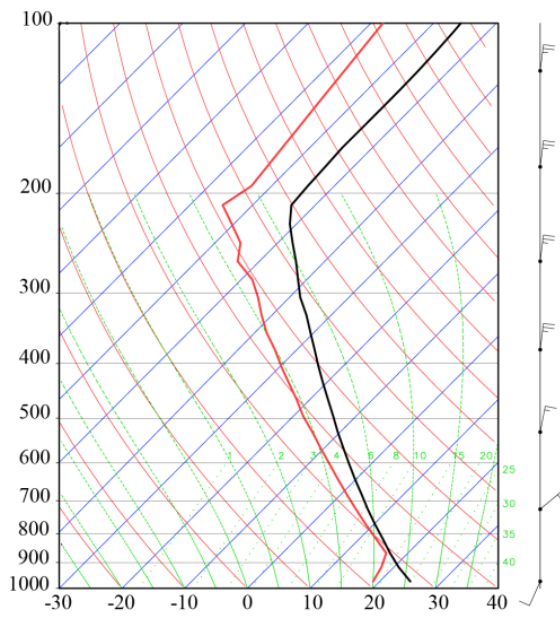

Figure 1. The baseline thermodynamic sounding profile used in the simulation.

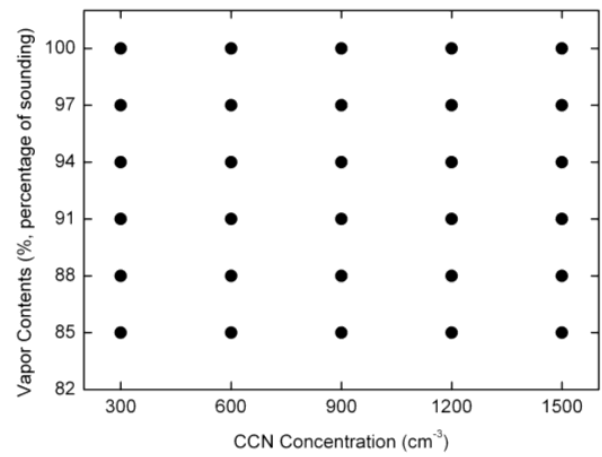

Figure 2. Each point represents an individual simulation. The horizontal axis denotes simulations with increasing initial CCN concentrations. The vertical axis shows the water vapor content with respect to the sounding.

\section{Results and Discussion}

\subsection{Aerosol Effects on the Intensity of Electrical Activity and Sensitivity to Vapor Conditions}

Figure 3 shows the space-time peak values of the positive and negative charge densities at $18 \mathrm{~min}$ of simulation, i.e., before the first flash when the positive and negative charges had not yet been neutralized in the thunderstorm. The peak values of the positive and negative charge densities intuitively reflect the intensity of electrification intensity in the thunderstorm. In the cases with baseline sounding (without changing the water vapor condition), the peak value of the positive charge density increased significantly from 0.44 to $0.89 \mathrm{nC} \cdot \mathrm{m}^{-3}$ as the initial $\mathrm{CCN}$ concentration increased from 300 to $1500 \mathrm{~cm}^{-3}$ and the negative charge density changed from -0.86 to $-1.47 \mathrm{nC} \cdot \mathrm{m}^{-3}$ as the initial $\mathrm{CCN}$ concentration increased. Under conditions with ample amounts of water vapor, the electrical activity of the thunderstorm was significantly enhanced with increasing concentrations of aerosols. As the vapor mixing ratio decreased, the peak values of the positive and negative charge densities also decreased with respect to the baseline sounding and were $<0.1 \mathrm{nC} \cdot \mathrm{m}^{-3}$ at vapor mixing ratios $<94 \%$. The response of the peak values of the positive and negative charge densities to an increase in aerosol concentration became less significant with decreasing water vapor content. For low amounts of water vapor, increasing the aerosol concentration had little impact on the peak values of the 
positive and negative charge densities. Hence, the effects of aerosols on the intensity of electrification were suppressed at low amounts of water vapor, leading to a lower sensitivity of the intensity of electrification to changes in aerosol concentration.
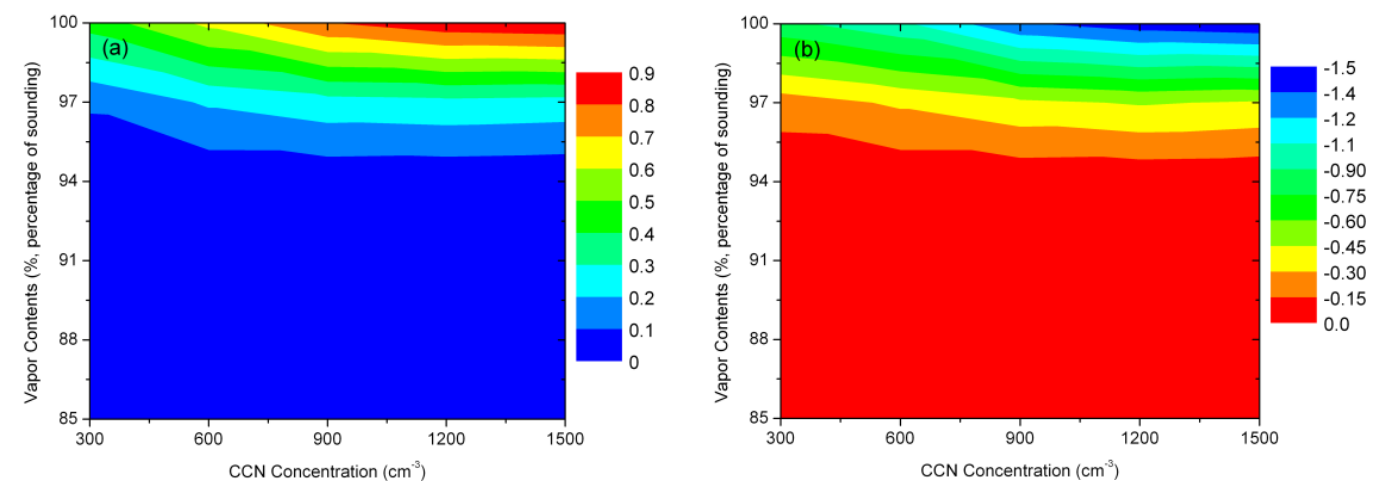

Figure 3. Peak values of (a) positive and (b) negative charge density $\left(\mathrm{nC} \cdot \mathrm{m}^{-3}\right.$ ) at $18 \mathrm{~min}$ of simulation under different vapor conditions and initial CCN concentrations.

This study considered the non-inductive electrification process that results from rebounding collisions of ice-graupel and snow-graupel. The number of ice-phase particles directly affects the intensity of electrical activity of the thunderstorm [31-33]. Figure 4 shows the mean concentration of ice crystals, snow particles, and graupel particles at $18 \mathrm{~min}$ of simulation under different vapor conditions and initial CCN concentrations. For the cases with baseline sounding, the mean concentrations of ice crystals, snow particles, and graupel particles increased by $12 \%, 40 \%$, and $36 \%$, respectively, when the initial CCN concentration was increased from 300 to $1500 \mathrm{~cm}^{-3}$. As the aerosol concentration increased, more ice-phase particles were produced in the thunderstorm and participated in the collision separation process under conditions with sufficient vapor, enhancing the thunderstorm electrification process. Previous studies [1-3] have suggested that as more ice-phase particles participate in the process of collision separation, the intensity of electrical activity is enhanced. As the amount of water vapor decreases, the response of the concentrations of ice crystals, snow particles, and graupel particles to changes in the aerosol concentration becomes less significant, especially for the water vapor contents $<91 \%$ of that for the baseline sounding. The effect of aerosol particles on the concentration of ice-phase particles is suppressed by decreasing the water vapor content, leading to a lower sensitivity of the intensity of electrical activity to a change in the aerosol concentration. Because the electrification process is dominated by the collision separation between ice-phase particles, the intensity of electrical activity, which is directly influenced by the number of ice-phase particles, becomes less sensitive to increasing aerosol concentrations at lower water vapor contents (Figure 3).
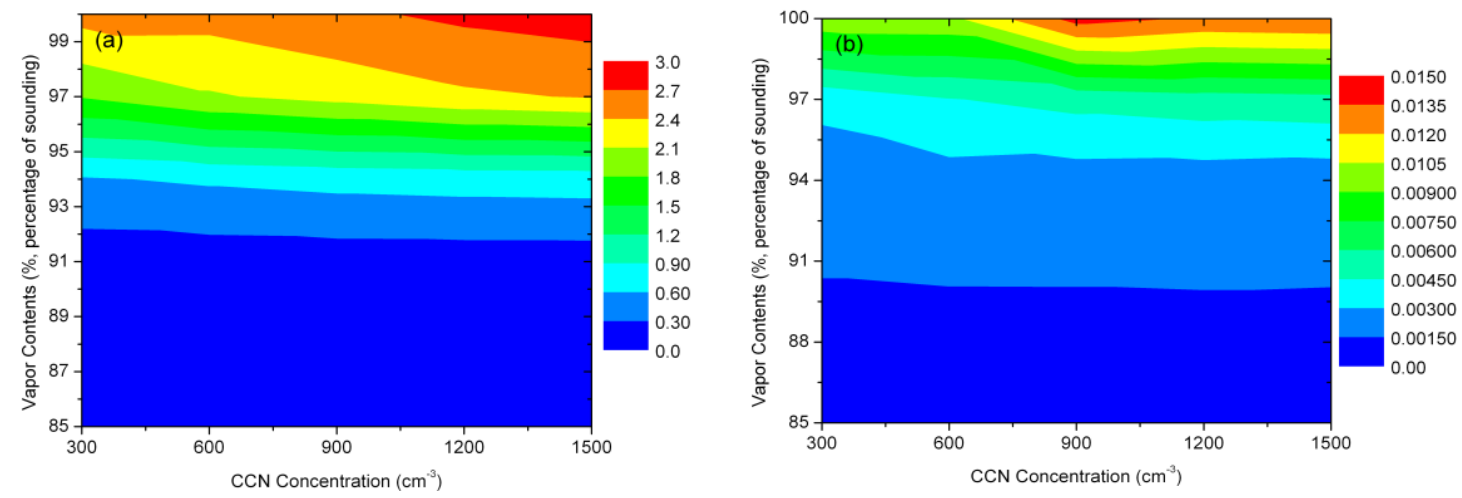

Figure 4. Cont. 


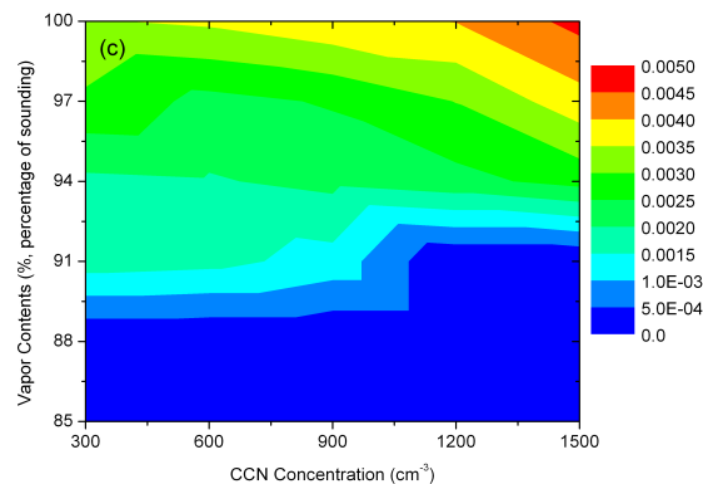

Figure 4. Mean concentration (in $\mathrm{cm}^{-3}$ ) of (a) ice crystals, (b) snow particles, and (c) graupel particles at $18 \mathrm{~min}$ of simulation under different vapor conditions and initial CCN concentrations.

The effects of aerosols on the intensity of lightning at different water vapor contents and initial $\mathrm{CCN}$ concentrations is shown by the mean flash rate (Figure 5). In the cases with baseline sounding, the mean flash rate was higher and increased with increasing initial CCN concentration. The mean flash rate was increased by about $16.7 \%$ as the initial CCN concentration changed from 300 to $1500 \mathrm{~cm}^{-3}$. The electrification processes in thunderstorms are caused by rebounding collisions between ice-phase particles [34]. As the thunderstorm develops, the charges carried by ice-phase particles accumulate and this will lead to an increase in the electric field in the cloud. When the electric field exceeds the discharge threshold, a flash is triggered and part of the charge is neutralized; the electric field will then be below the discharge threshold. The electric field will accumulate again until the next flash is triggered $[23,24,28,31]$. As the water vapor content decreased, the mean flash rate decreased by at least $86 \%$. This illustrates the importance of water vapor content in the intensity of electrical activity. The increase in the flash rate with increasing aerosol concentrations weakened with a decrease in the water vapor content. At the lowest water vapor content ( $85 \%$ of the baseline sounding), the mean flash rate remained almost constant with increasing aerosol concentrations. Previous studies [1-4] have also indicated that an increase in the concentration of aerosol particles enhances the intensity of electrical activity. However, this does not apply to all thunderstorms under different conditions, and there are still uncertainties in the effects of aerosol on thunderstorm microphysics and electrification processes. At low water vapor contents, the intensity of electrical activity is little changed with increasing aerosol concentrations, which shows that the effects of aerosol on thunderstorm electrical activity are heavily dependent on the amount of water vapor present.

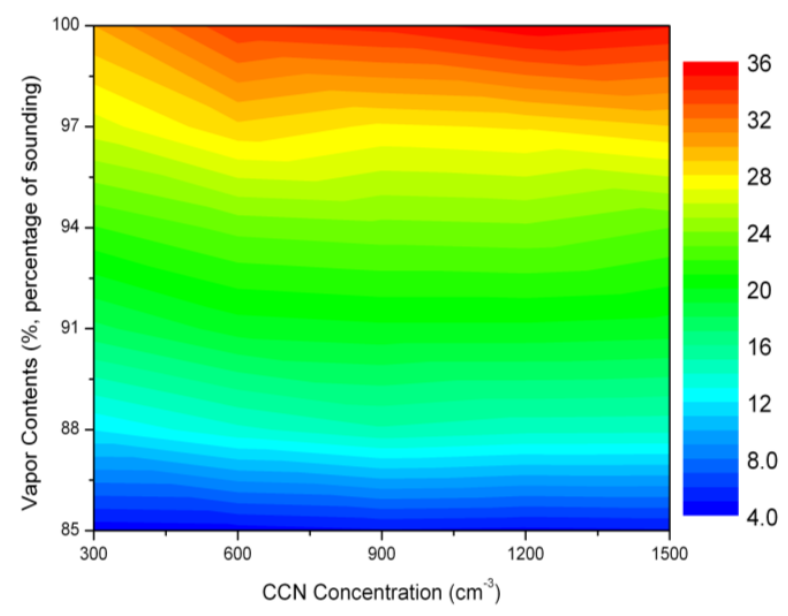

Figure 5. Mean flash rate (flash $\mathrm{min}^{-1}$ ) for different vapor contents and initial CCN concentrations. 
Aerosol particles affect thunderstorm electrical activity by influencing the hydrometeors and related microphysical processes. Figure 6 shows the variation in the mean number concentration of cloud droplets, raindrops, ice crystals, snow particles, and graupel particles with time for initial $\mathrm{CCN}$ concentration of 300 and $1500 \mathrm{~cm}^{-3}$. The concentration of cloud droplets in a thunderstorm significantly increases and the size of the droplets decreases with increasing concentrations of aerosols (Figure 6a). In the simulations with the lowest water vapor content ( $85 \%$ of the baseline sounding), the increase in the concentration of cloud droplets caused by increasing initial CCN concentrations was smaller than in the simulations with ample amount of water vapor ( $100 \%$ of the baseline sounding). Fewer droplets were activated at lower amounts of water vapor, when the concentration of aerosol was greater. As the concentration of aerosol particles increased, the size of the cloud droplets decreased and the collision and coalescence processes were suppressed, resulting in fewer raindrops. Figure $6 \mathrm{~b}$ shows that increasing the aerosol concentration had a significant impact on the concentrations of cloud droplets and raindrops after 25 min of simulation with an ample amount of water vapor. The difference in the concentration of raindrops caused by changes in the aerosol concentration became unremarkable at the lowest water vapor content ( $85 \%$ of the baseline sounding). Fan et al. [18] showed that aerosol effects on precipitation were significant under relatively humid conditions, but became less significant under conditions with limited water vapor. The water vapor content affected the concentration of ice crystals, which decreased with decreasing water vapor content. However, the influence of aerosol particles on the concentration of ice crystals was less obvious and there was little difference in the concentration of ice crystals at different aerosol concentrations under both ample water vapor (100\% of the baseline sounding) and limited water vapor ( $85 \%$ of the baseline sounding) conditions. For high amounts of water vapor, the concentration of snow particles increased with increasing aerosol concentrations, but changed very little at the lowest water vapor content. In this study, the non-inductive electrification processes result from rebounding collisions of ice-graupel and snow-graupel. Miller et al. [35] and Mansell et al. [2] suggested that graupel particles play a part in the electrification processes and have a direct impact on thunderstorm electrical activity. Figure 6e shows that increasing aerosol concentrations resulted in the formation of more graupel particles, which is more significant under the conditions of ample amounts of water vapor. In the simulations with a low water vapor content, increasing the aerosol concentration had little effect on the concentration of graupel particles.
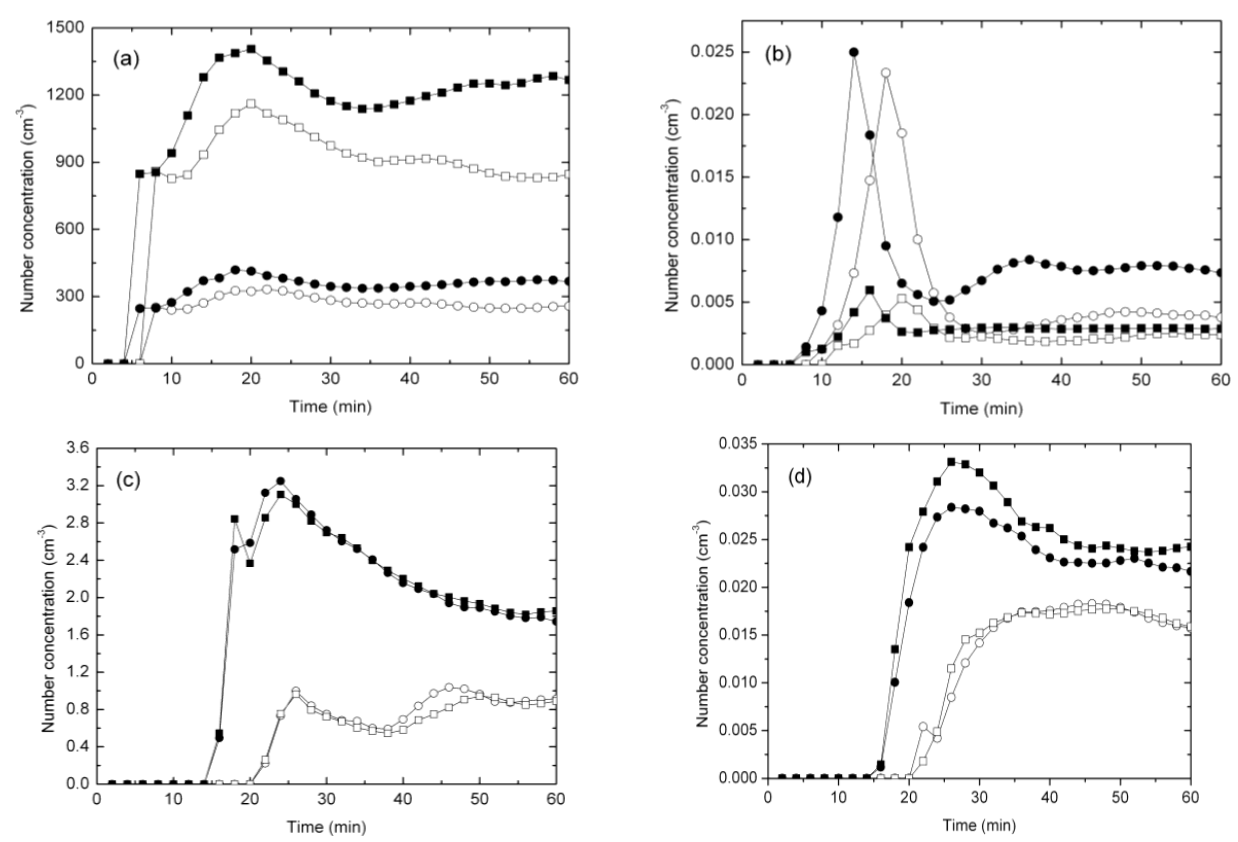

Figure 6. Cont. 


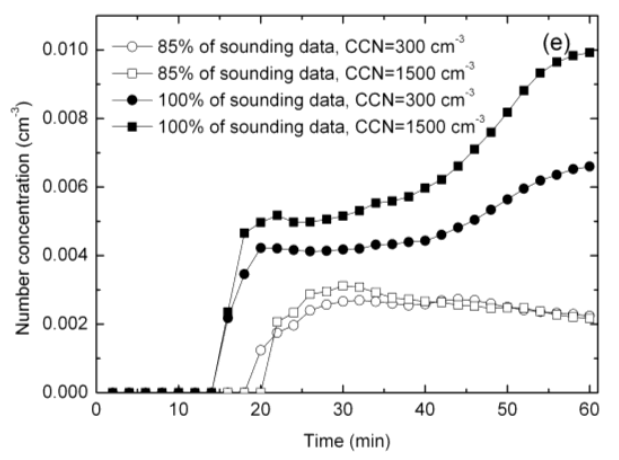

Figure 6. Mean concentration of (a) cloud droplet, (b) raindrops, (c) ice crystals, (d) snow particles, and (e) graupel particles over time for initial CCN of 300 and $1500 \mathrm{~cm}^{-3}$ under water vapor conditions of $85 \%$ and $100 \%$ of baseline sounding.

These results are consistent with previous studies [36-42] in which increasing the initial CCN concentrations reduced the droplet size, enhanced condensation growth, and reduced the efficiency of the collision and coalescence of droplets. This led to more small droplets being transported above the freezing level and enhanced the growth of ice-phase particles under conditions of ample amounts of water vapor. Under conditions of limited water vapor, the increase in the concentration of cloud droplets caused by aerosols became less significant and fewer small droplets were carried above the freezing level, leading to fewer raindrops and ice-phase particles. Under conditions of ample amounts of water vapor, there was an obvious influence of aerosols on the ice-phase particles and related microphysical processes, resulting in a significant change in the electrical activity of thunderstorms. In addition, the weak ice-phase microphysical processes and fewer ice-phase particles suppressed the influence of aerosols on electrical activity, leading to a lower effect of aerosols on the intensity of electrical activity under limited water vapor conditions (Figure 5).

Graupel particles are very important in electrification processes [35], and aerosols have different effects on graupel particles for different amounts of water vapor. Figure 7 shows the mass conversion rates of graupel particles, including the accretion of snow by cloud droplets to form graupel, the accretion of ice crystals by rain to form graupel, the accretion of rain by graupel particles, and the accretion of snow by rain to form graupel particles. The conversion rate of the accretion of snow by cloud droplets to form graupel particles is significantly increased with increasing aerosol concentrations under conditions with ample amounts of water vapor, but is very low or almost zero when there are only low amounts of water vapor. Under conditions with ample amounts of water vapor, the conversion rate of the accretion of ice crystals by rain to form graupel particles increases with increasing aerosol concentrations, mainly due to the larger ice crystals present under polluted conditions. The effects of aerosol on the conversion rate under conditions with ample amounts of water vapor were consistent with previous studies $[43,44]$. The conversion rate decreased at lower amounts of water vapor, leading to a lower sensitivity to increasing aerosol concentrations. There were more graupel particles as the aerosol concentration increased with ample amounts of water vapor, leading to an increase in the conversion rate for the accretion of rain by graupel. The conversion rate of accretion of rain by graupel was relatively lower for lower amounts of water vapor, resulting in a lower response to the aerosol concentration. When there were ample amounts of water vapor, the number of snow particles increased with increasing aerosol concentrations; however, the concentration of raindrops decreased under polluted conditions and the concentration of snow was very low, resulting in a lower conversion rate for the accretion of snow by rain to form graupel. There was no obvious effect of the aerosol concentration on the conversion rate of the accretion of snow by rain at lower amounts of water vapor. 


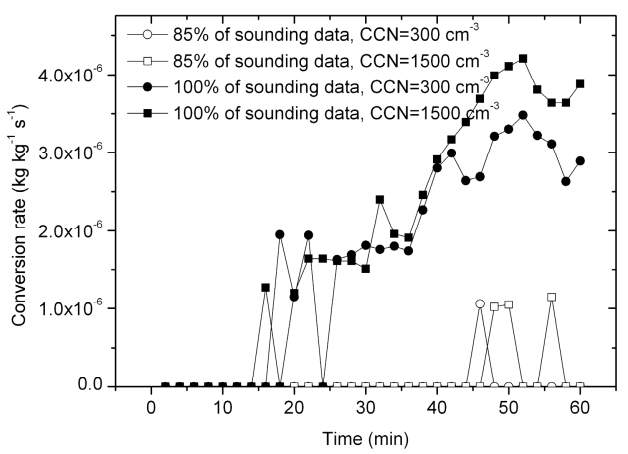

(a)

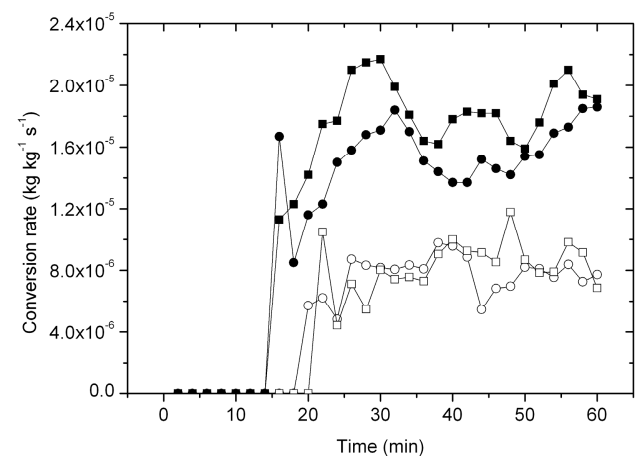

(c)

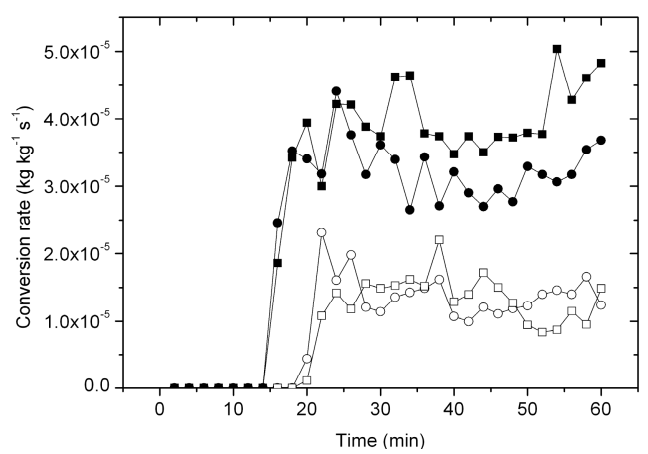

(b)

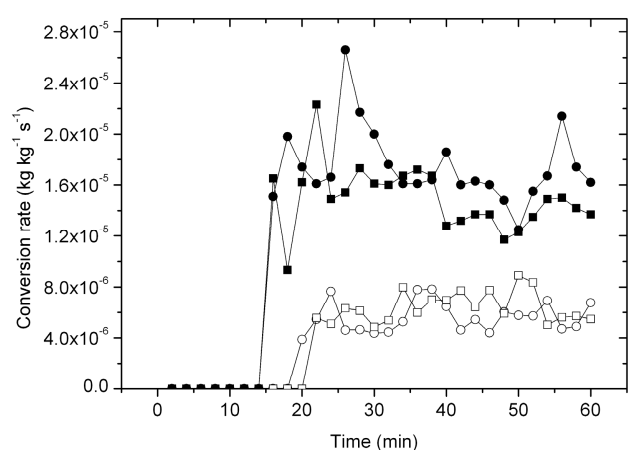

(d)

Figure 7. Mass conversion rates of graupel particles with time for initial CCN of 300 and $1500 \mathrm{~cm}^{-3}$ under water vapor conditions of $85 \%$ and $100 \%$ of baseline sounding, including (a) the accretion of snow by cloud droplets to form graupel, (b) the accretion of ice crystals by rain to form graupel, (c) the accretion of rain by graupel, and (d) the accretion of snow by rain to form graupel.

Under conditions with ample amounts of water vapor, the conversion rates for the accretion of snow by cloud droplets to form graupel, the accretion of ice crystals by rain to form graupel, the accretion of rain by graupel, and the accretion of snow by rain to form graupel increased with increasing aerosol concentrations, leading to more graupel. When the water vapor content decreased, the conversion rates for graupel were suppressed and the effect of aerosol concentration on the graupel particles was also suppressed. Hence, the effect of aerosol concentration on ice-phase particles depended on the amounts of water vapor present.

\subsection{Response of Aerosol Effects on the Charge Structures to the Amount of Water Vapor Present}

Figure 8 shows the peak values of positive and negative charge density. In the simulations with baseline sounding (ample amount of water vapor), the change in aerosol concentration affected the charge structures. When the initial CCN concentration was $300 \mathrm{~cm}^{-3}$, the structure retained dipolar throughout the simulation. However, when the initial CCN concentration was $1500 \mathrm{~cm}^{-3}$, the charge structure was dipolar in the initial stage of simulation and then a new negative charge region appeared above the main positive charge center after $34 \mathrm{~min}$ of simulation. When the water vapor content decreased to $94 \%$ of the baseline sounding, the charge structure of the thunderstorm was still dipolar at low aerosol concentrations and there was also a new negative charge region above the main positive charge center; however, the negative charge region appeared late and decreased. As the water vapor content decreased further to $85 \%$ of the baseline sounding, the charging process of thunderstorm appeared later, and the charge structure remained dipolar as the initial CCN concentration increased. Therefore, the reduction in water vapor content suppressed the effects of the aerosol concentration on the charge structure. 

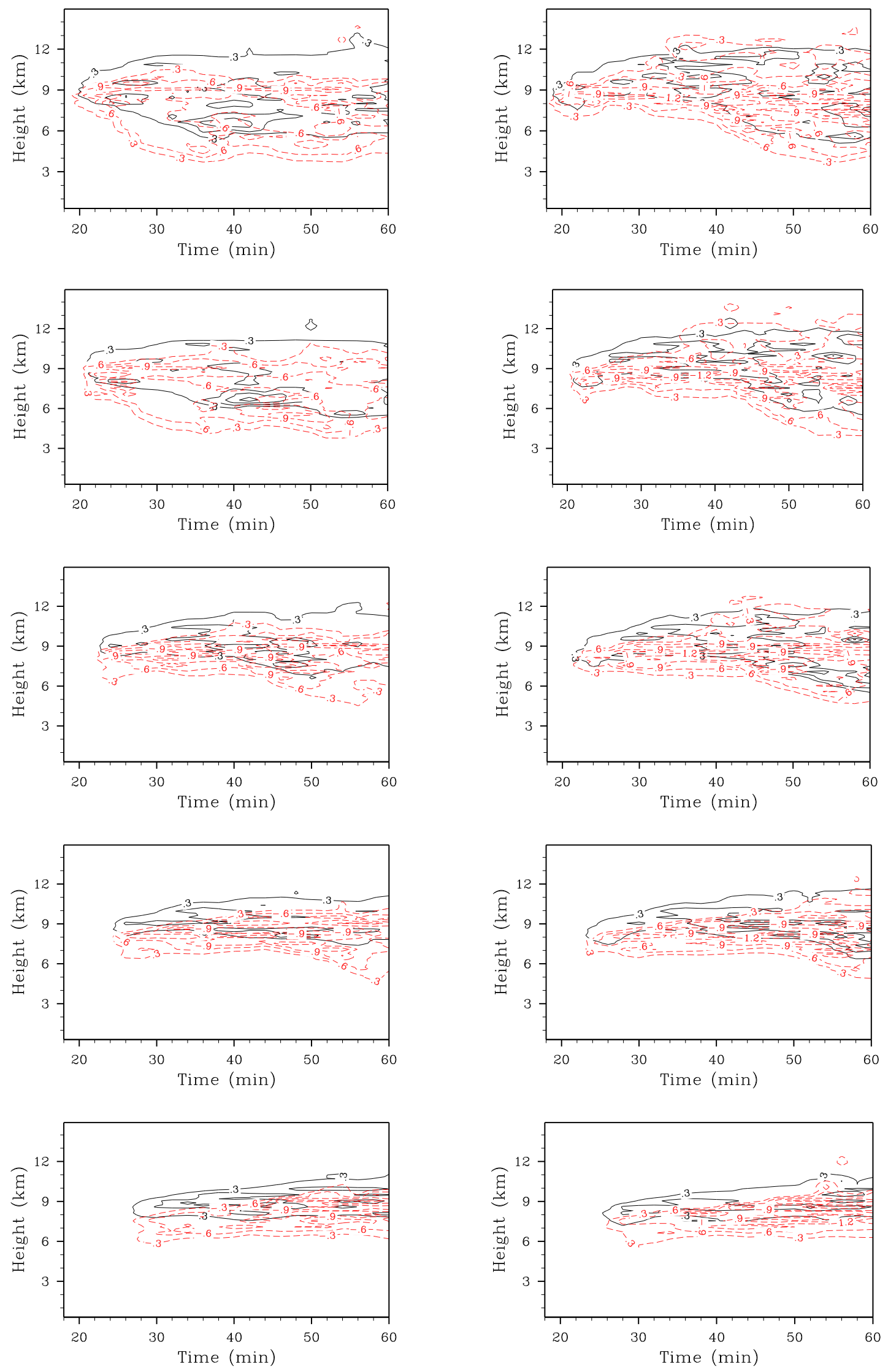

Figure 8. Cont. 


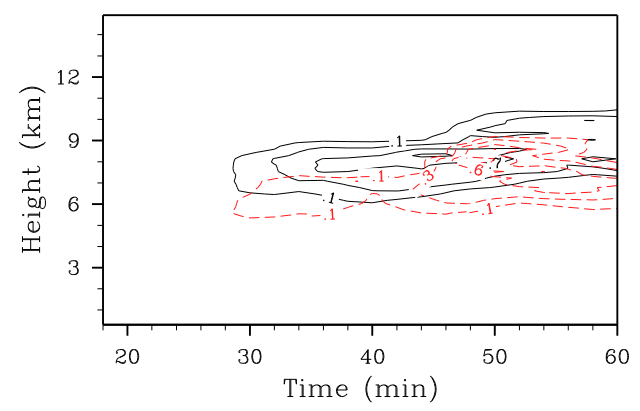

(a)

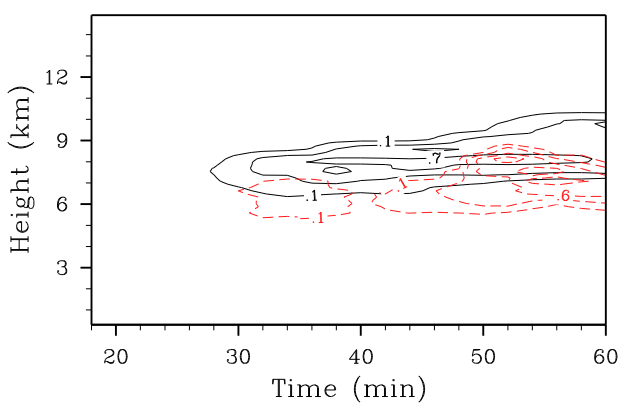

(b)

Figure 8. Time-height peak values of positive (solid line) and negative (red dashed line) charge density $\left(\mathrm{nC} \cdot \mathrm{m}^{-3}\right)$ for initial concentrations of $\mathrm{CCN}$ of $300(\mathbf{a})$ and $1500 \mathrm{~cm}^{-3}$ (b) under water vapor conditions from $100 \%$ to $85 \%$ of the baseline sounding at $3 \%$ intervals (from top to bottom).

The main charging mechanism considered in this study was the non-inductive electrification resulting from rebounding collisions of ice-graupel and snow-graupel. The charge structures directly depended on the polarity of the charge carried by the ice-phase particles. As a result of the large number of ice crystals, the charging states of the ice crystals were analyzed. Figure 9 shows the peak values of the positive and negative charge density carried by the ice crystals. Under ample water vapor conditions (baseline sounding), the ice crystals were mainly distributed at a height of 7-10 km and were always positively charged when the initial CCN concentration was $300 \mathrm{~cm}^{-3}$. As the initial $\mathrm{CCN}$ concentration is increased to $1500 \mathrm{~cm}^{-3}$, the ice crystals were distributed more widely (at a height of 6-11.5 km), with the ice crystals becoming positively charged in the first 30 min of simulation and some of the ice crystals above a height of $8 \mathrm{~km}$ becoming negatively charged later. This shows the charge reversal of ice crystals in this region. When the water vapor content was $94 \%$ of that in the baseline sounding, the ice crystals charged positively when the initial CCN concentration was $300 \mathrm{~cm}^{-3}$, whereas some of the ice crystals above a height of $8 \mathrm{~km}$ became negatively charged with increasing concentrations of aerosol. The distribution of the negative charge region decreased with decreasing amounts of water vapor. As the amount of water vapor decreased further to $85 \%$ of that in the baseline sounding, the distribution of the charge carried by the ice crystals decreased and the ice crystals charged positively only. Therefore, the negatively charged region that appeared above the main positive charge center under conditions of ample amounts of water vapor and high initial CCN concentrations was caused by the negative charge carried by the ice crystals. Under conditions with a low water vapor content, increasing aerosol concentrations did not lead to a reversal of charge carried by the ice particles, resulting in similar charge structures between clean and polluted simulations.
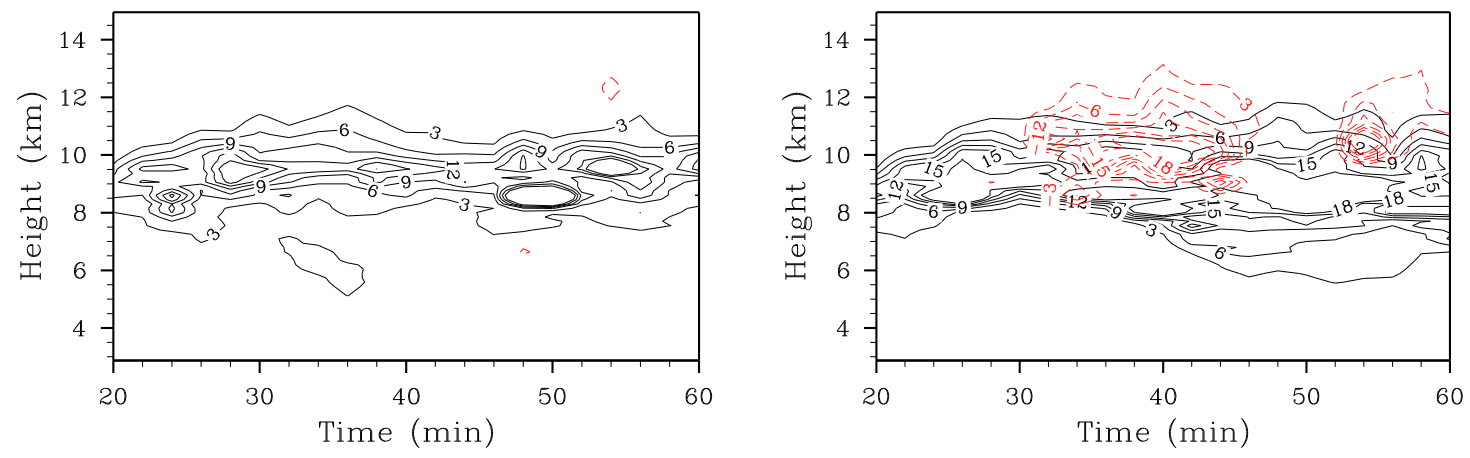

Figure 9. Cont. 

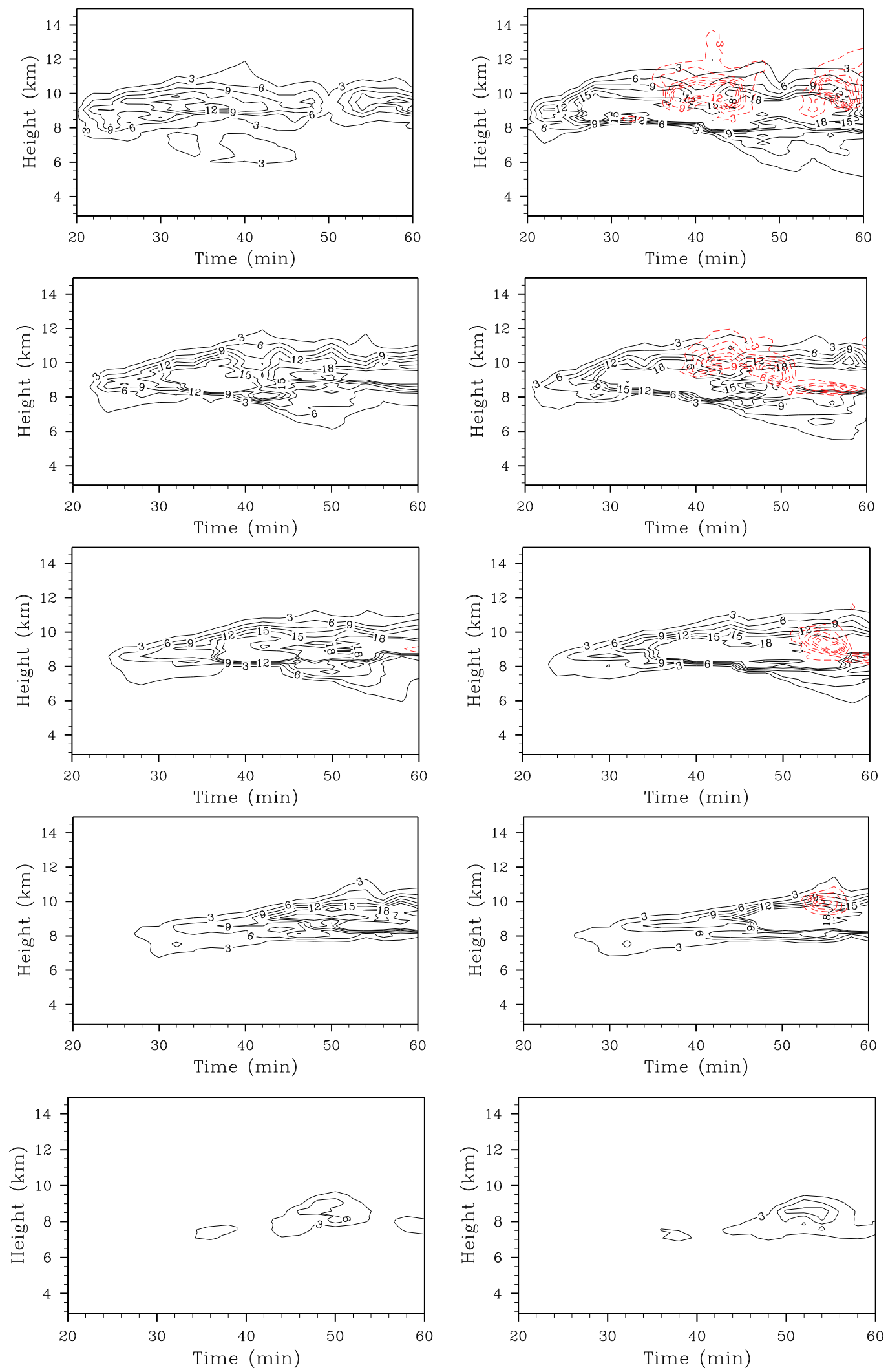

(a)

(b)

Figure 9. Time-height peak values of positive and negative charge density carried by ice crystals for initial concentrations of CCN of 300 (a) and $1500 \mathrm{~cm}^{-3}$ (b) under water vapor conditions from $100 \%$ to $85 \%$ of baseline sounding at $3 \%$ intervals (from top to bottom). 
The polarity of charges carried by ice particles after the rebounding collision depends on the difference between the RAR and the $R A R_{C}$ [34]. If $R A R>R A R_{C}$, then the graupel particles carry positive charge and the rebounding ice crystals or snow particles carry negative charge. When RAR $<$ RAR $_{C}$, graupel particles carry negative charge, and the rebounding ice crystals or snow particles carry positive charge. To analyze the high-level negative charge carried by the ice crystals, the positive deviation of RAR and RAR ${ }_{C}$ was plotted in Figure 10. In the simulations with the baseline sounding, the region of the positive deviation of RAR and RAR $_{C}$ became broader with increasing aerosol concentration, especially above a height of $8 \mathrm{~km}$, which is the main region for rebounding collisions between ice particles. This led to a negative charge carried by ice crystals and a positive charge carried by graupel particles in this region. When the water vapor content decreased to $94 \%$ of the baseline sounding, the distribution of the positive deviation of RAR and RAR $\mathrm{R}_{\mathrm{C}}$ decreased. As the water vapor content decreased further to $88 \%$ of the baseline sounding, the distribution of the positive deviation of RAR and RAR $R_{C}$ decreased further and was mainly distributed below a height of $7 \mathrm{~km}$, where the collision of ice-phase particles was too low. There was therefore no change in the charge polarity of ice particles with increasing aerosol concentration when the amount of water vapor was low.
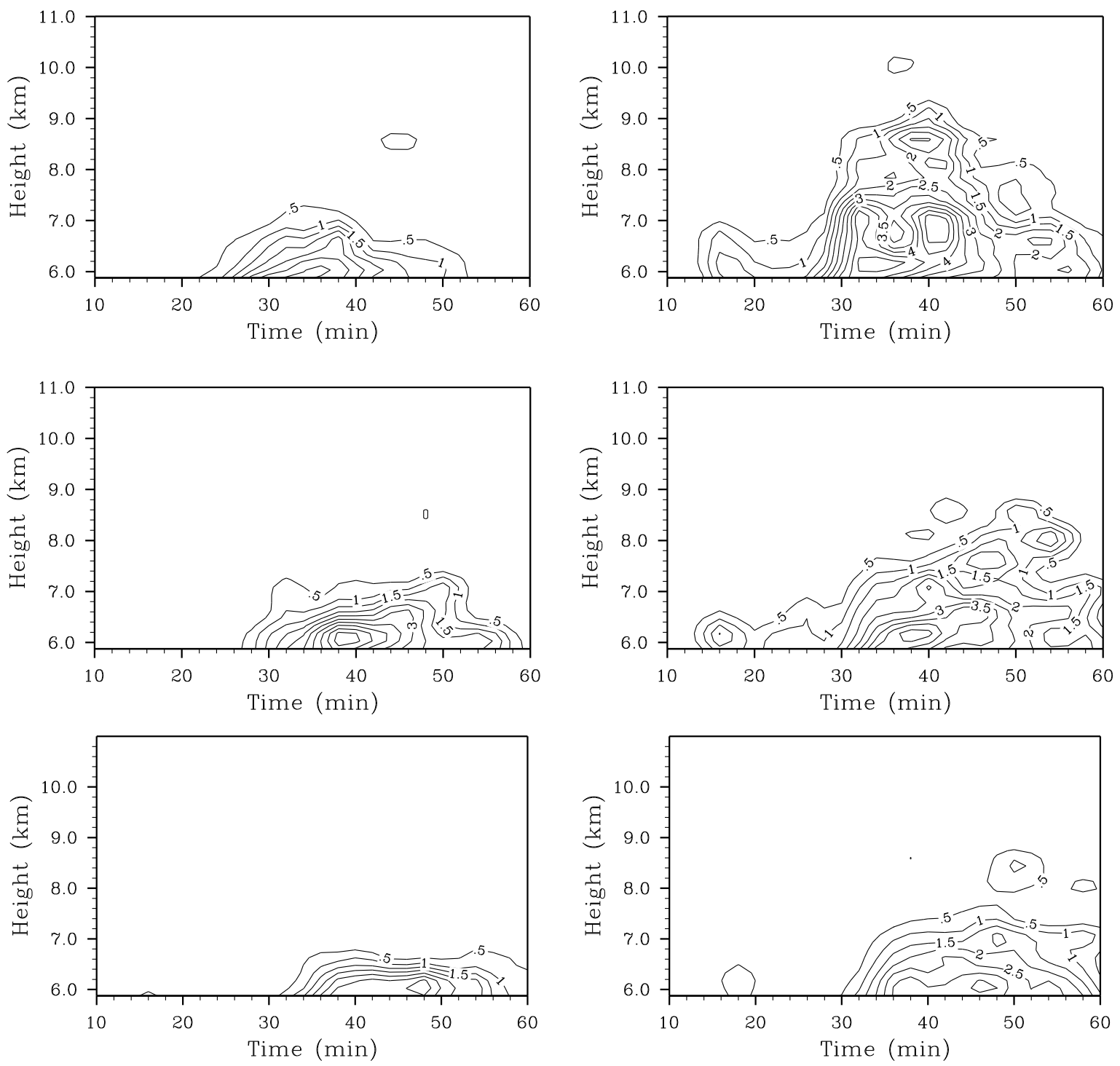

Figure 10. Cont. 

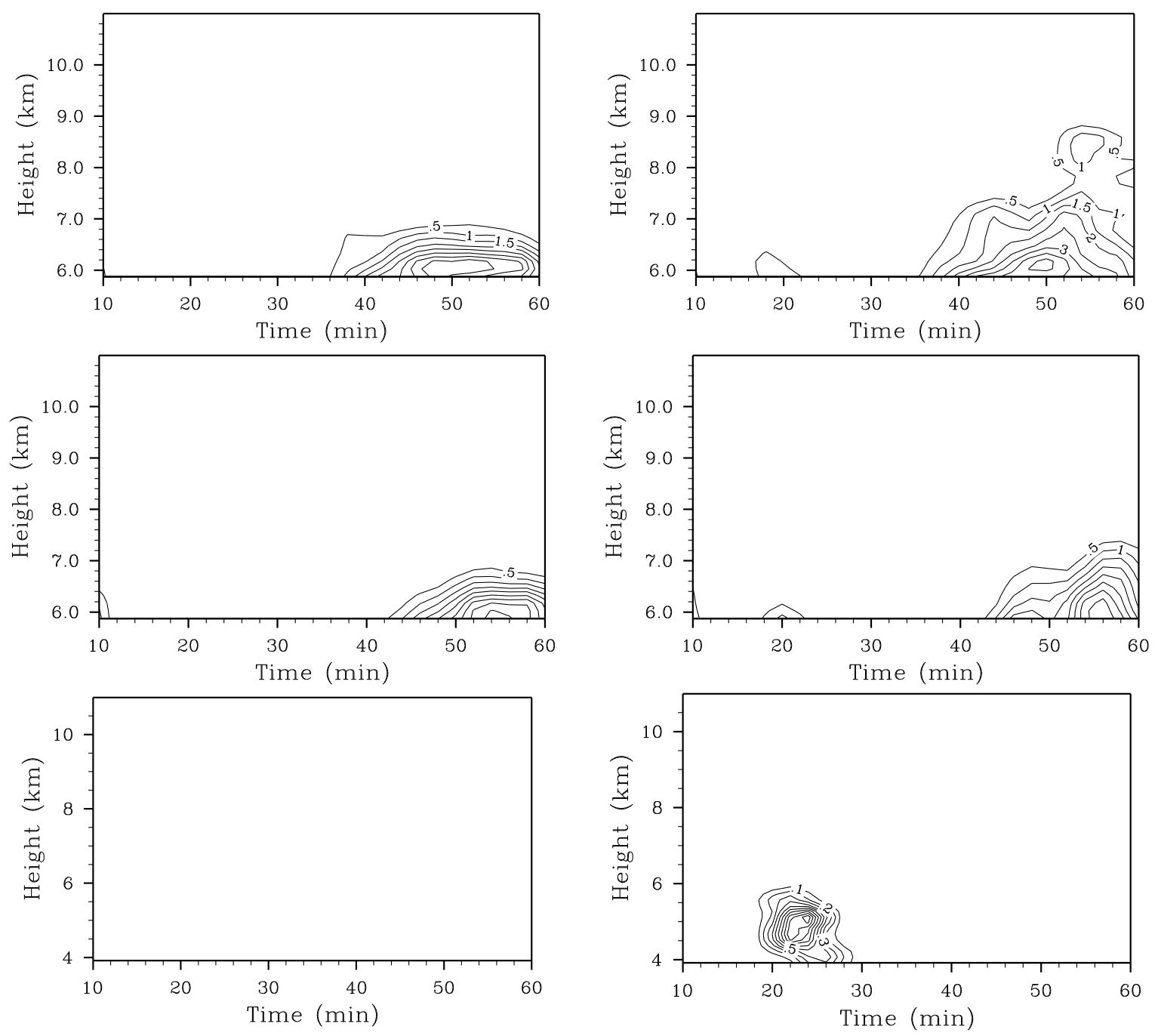

(a)

(b)

Figure 10. Time-height positive deviation of RAR and $R A R_{C}\left(\right.$ in $g \cdot \mathrm{m}^{-2} \cdot \mathrm{s}^{-1}$ ) for initial concentrations of CCN of 300 (a) and $1500 \mathrm{~cm}^{-3}$ (b) under the water vapor conditions from $100 \%$ to $85 \%$ of baseline sounding at $3 \%$ intervals (from top to bottom).

In this model, $\mathrm{RAR}_{C}$ is a function of temperature and remains unchanged at the same temperature, whereas RAR depends on the liquid water content (see Figure 11). In the simulations with baseline sounding, the distribution of liquid water was higher with increasing aerosol concentrations and reached a height of $9.5 \mathrm{~km}$ after $30 \mathrm{~min}$ of simulation. In polluted cases, the liquid water content was greater, especially at a height of 6-8 $\mathrm{km}$ after $30 \mathrm{~min}$ of simulation, because more small droplets were transported to higher levels. As the water vapor content decreased to $94 \%$ of the baseline sounding, the distribution of liquid water content became lower at a height of $9 \mathrm{~km}$, although an increasing concentrations of aerosol increased the liquid water content. When the water vapor content decreased further to $85 \%$ of the baseline sounding, the distribution of liquid water was very close to that of the increase in aerosol concentration and was mainly found below $8 \mathrm{~km}$. Under conditions of limited water vapor, the lower sensitivity of the cloud droplets to the aerosol concentration resulted in the liquid water content above the freezing level remaining constant as aerosol concentration increased. 

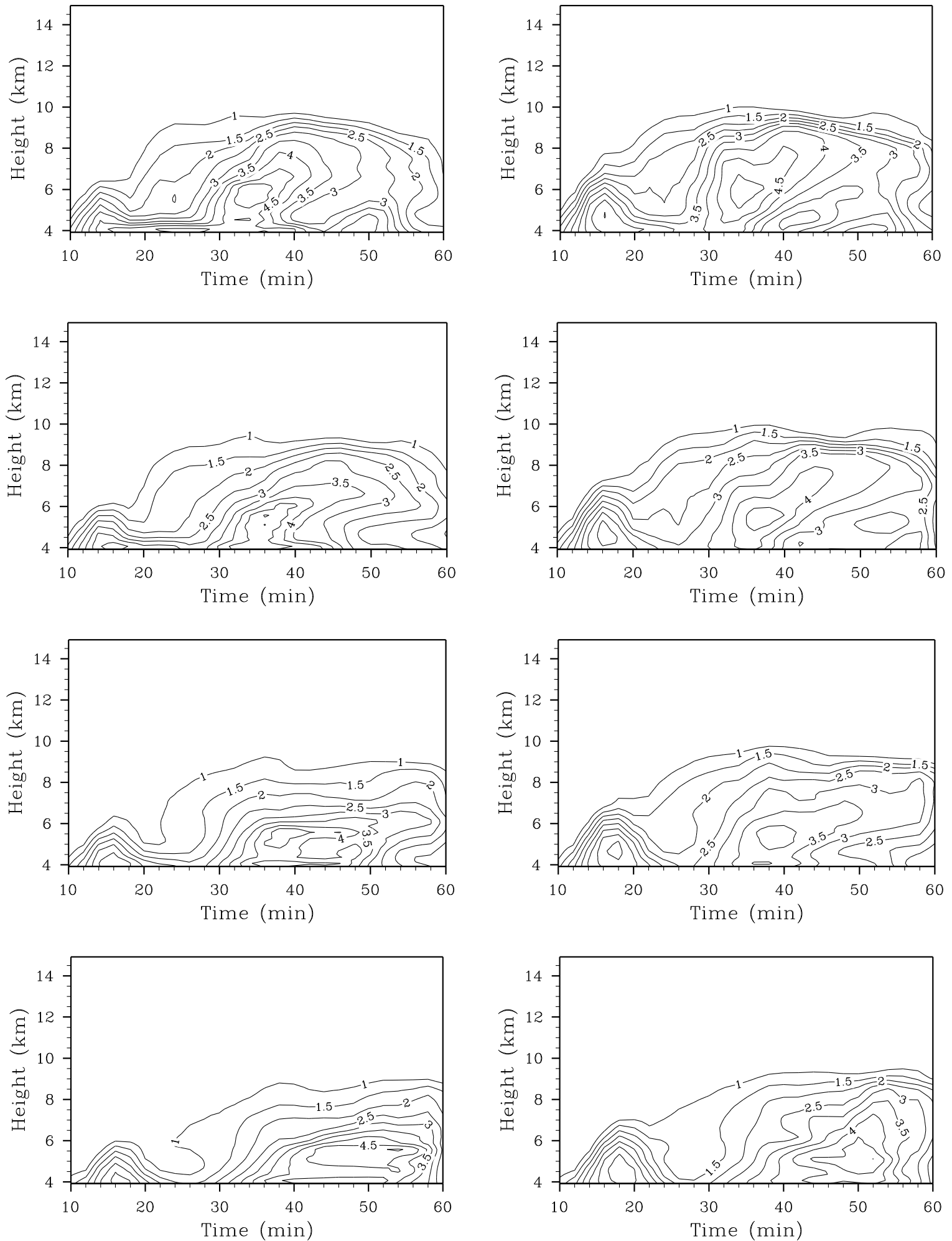

Figure 11. Cont. 

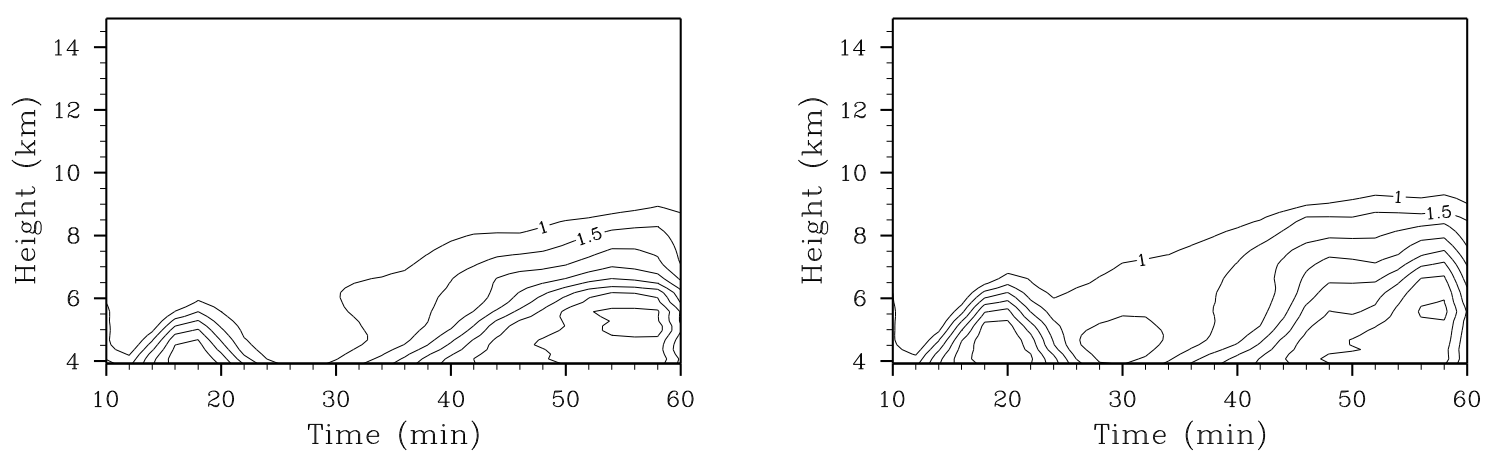

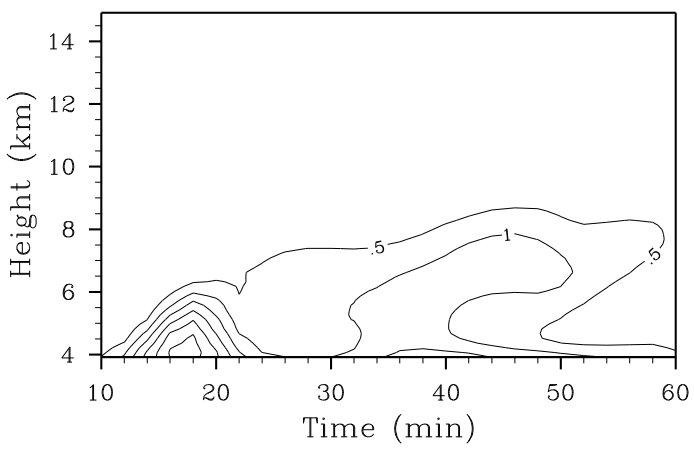

(a)

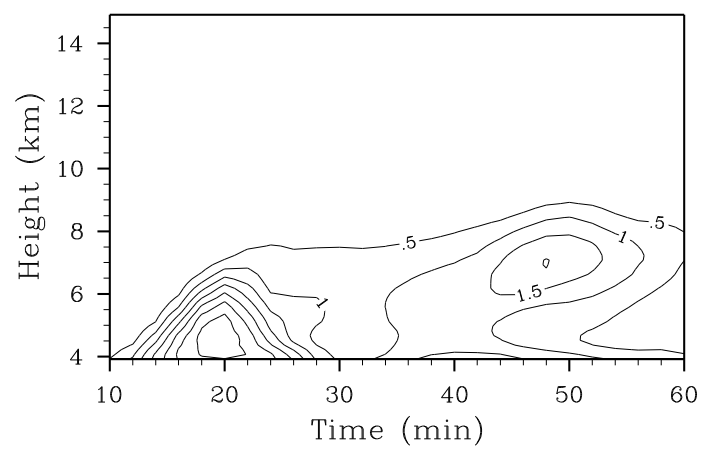

(b)

Figure 11. Time-height of liquid water content for initial concentrations of CCN of 300 (a) and $1500 \mathrm{~cm}^{-3}$ (b) under the water vapor conditions from $100 \%$ to $85 \%$ of the baseline sounding at $3 \%$ intervals (from top to bottom).

Under conditions of ample amounts of water vapor, more cloud droplets were transported above the freezing level for polluted cases, leading to a higher liquid water content and a positive deviation of RAR and RAR $_{C}$ at high levels. In this region, a charging reversal was seen for ice particles during the rebounding collision process, resulting in the graupel becoming positively charged, the ice crystals/snow particles becoming negatively charged, and a small negatively charged region appearing above the main positive charge center. As the water vapor content decreased, a lower sensitivity of the cloud droplets to an increase in the aerosol concentration led to a smaller difference in the liquid water content between the clean and the polluted simulations with a lower distribution for liquid water. There was no positive deviation of RAR and $\mathrm{RAR}_{C}$ in the region with rebounding collisions of ice particles, resulting in no change in the charge structure with increasing aerosol concentrations. Hence, the reduction in the water vapor content suppressed the effects of aerosols on the charge structure.

\section{Summary and Conclusions}

Non-inductive electrification and a simple discharge process were coupled with Morrison two-moment bulk mixed-phase microphysics scheme in the WRF model. Thirty susceptibility tests were simulated to explore the effects of aerosol concentration on the development of electrification in thunderstorms under different vapor conditions by varying the initial $\mathrm{CCN}$ concentration and the water vapor content below the freezing level.

Our results showed that the previously reported [1-5] enhancement in the lightning activity of thunderstorms as the concentration of aerosols increases is not universal. Under conditions of ample amounts of water vapor, increasing the aerosol concentration resulted in the formation of more small cloud droplets, reducing the collision coalescence efficiency of the cloud droplets and suppressing the warm rain process. More small droplets were transported to above the freezing level and this enhanced the lightning activity resulting from the participation of more ice particles in the electrification process. As the water vapor content decreased, the sensitivity of cloud droplets, rain droplets, and ice particles 
to an increase in the aerosol concentration decreased, leading to smaller differences in the intensity of lighting activities between the clean and polluted simulations.

Under conditions with ample amounts of water vapor, more cloud droplets were transported above the freezing level in polluted simulations, leading to the formation of more liquid water and the charge reversal of ice particles at high levels. This resulted in the formation of a negative charge region above the main positive charge center in the polluted simulations. Under conditions with low amounts of water vapor, the profile of effective liquid water content in the polluted cases was close to that in the clean cases, resulting in a similar charge distribution between the clean and polluted simulations as a result of the low amounts of water vapor reducing the sensitivity of the liquid water content to the concentration of aerosol.

A decreasing water vapor content below freezing level hinders the development of thunderstorms, especially in the ice-phase processes. The effects of aerosols on the electrical processes of thunderstorms depended on the liquid water content and the concentration of ice particles above the freezing level. Reducing the water vapor content below the freezing level weakened the ice-phase processes and then suppressed the effects of aerosols on the intensity of electrification and the charge structure. The effects of aerosol concentration on cloud microphysical processes are very complicated [45], resulting in different effects of aerosol concentrations on the electrical processes of thunderstorms at different stages of development with a strong dependency on the condition of water vapor below the freezing level.

Acknowledgments: Support from the National Basic Research and Development (973) Program of China (2014CB441403, 2014CB441401), the Scientific Research Foundation of CUIT (KYTZ201601), the Science and Technology Achievements Transformation Program of Sichuan Provincial Department of Education (16CZ0021), and the Key Program of Beijing Municipal Natural Science Foundation (8141002) is gratefully acknowledged.

Author Contributions: Pengguo Zhao, Yan Yin, and Hui Xiao conceived and designed the experiments; Pengguo Zhao, Yunjun Zhou, and Jia Liu performed the experiments; Pengguo Zhao and Hui Xiao analyzed the simulation results and wrote the paper.

Conflicts of Interest: The authors declare no conflict of interest.

\section{References}

1. Mitzeva, R.P.; Latham, J.; Petrova, S.A. comparative modeling study of the early electrical development of maritime and continental thunderstorms. Atmos. Res. 2006, 82, 26-36. [CrossRef]

2. Mansell, E.R.; Ziegler, C.L. Aerosol effects on simulated storm electrification and precipitation in a two-moment bulk microphysics model. J. Atmos. Sci. 2013, 70, 2032-2050. [CrossRef]

3. Zhao, P.; Yin, Y.; Xiao, H. The effects of aerosol on development of thunderstorm electrification: A numerical study. Atmos. Res. 2015, 153, 376-391. [CrossRef]

4. Bell, T.L.; Rosenfeld, D.; Kim, K.M.; Yoo, J.M.; Lee, M.I.; Hahnenberger, M. Midweek increase in U.S. summer rain and storm heights suggests air pollution invigorates rainstorms. J. Geophys. Res. 2008, 113. [CrossRef]

5. Wang, Y.; Wan, Q.; Meng, W.; Liao, F.; Tan, H.; Zhang, R. Long-term impacts of aerosols on precipitation and lightning over the Pearl River Delta megacity area in China. Atmos. Chem. Phys. 2011, 11, 12421-12436. [CrossRef]

6. Stallins, J.A.; Carpenter, J.; Bentley, M.L.; Ashley, W.S.; Mulholland, J.A. Weekend-weekday aerosols and geographic variability in cloud-to-ground lightning for the urban region of Atlanta, Georgia, USA. Reg. Environ. Chang. 2013, 1, 137-151. [CrossRef]

7. Middey, A.; Chaudhuri, S. The reciprocal relation between lightning and pollution and their impact over Kolkata, India. Environ. Sci. Pollut. Res. 2013, 20, 3133-3139. [CrossRef] [PubMed]

8. Strikas, O.M.; Elsner, J.B. Enhanced cloud-to-ground lightning frequency in the vicinity of coal plants and highways in Northern Georgia, USA. Atmos. Sci. Lett. 2013, 14, 243-248. [CrossRef]

9. Kar, S.K.; Liou, Y.A. Enhancement of cloud-to-ground lightning activity over Taipei, Taiwan in relation to urbanization. Atmos. Res. 2014, 147, 111-120. [CrossRef]

10. Lyons, W.A.; Nelson, T.E.; Williams, E.R.; Cramer, J.A.; Turner, T.R. Enhanced positive cloud-to-ground lightning in thunderstorms ingesting smoke from fires. Science 1998, 282, 77-80. [CrossRef] [PubMed] 
11. Murray, N.D.; Orville, R.E.; Huffines, G.R. Effect of pollution from Central American fires on cloud-to-ground lightning in May 1998. Geophys. Res. Lett. 2000, 27, 2249-2252. [CrossRef]

12. Fernandes, W.C.; Pinto, I.R.C.A.; Pinto, O., Jr.; Longo, K.M.; Freitas, S.R. New findings about the influence of smoke from fires on the cloud-to-ground lightning characteristics in the Amazon region. Geophys. Res. Lett. 2006, 33. [CrossRef]

13. Altaratz, O.; Koren, I.; Yair, Y.; Price, C. Lightning response to smoke from Amazonian fires. Geophys. Res. Lett. 2010, 37. [CrossRef]

14. Saleeby, S.M.; Cotton, W.R.; Lowenthal, D.; Borys, R.D.; Wetzel, M.A. Influence of cloud condensat ion nuclei on orographic snowfall. J. Appl. Meteorol. Climatol. 2009, 48, 903-922. [CrossRef]

15. Saleeby, S.M.; Cotton, W.R.; Fuller, J. The cumulative impact of cloud droplet nucleating aerosols on orographic snowfall in Colorado. J. Appl. Meteorol. Climatol. 2011, 50, 604-625. [CrossRef]

16. Saleeby, S.M.; Cotton, W.R.; Messina, J.; Beem, K. Aerosol impacts on the microphysical growth processes of orographic snowfall. J. Appl. Meteorol. Climatol. 2013, 52, 834-852. [CrossRef]

17. Tao, W.; Li, X.; Khain, A.; Matsui, T.; Lang, S.; Simpson, J. Role of atmospheric aerosol concentration on deep convective precipitation: Cloud-resolving model simulation. J. Geophys. Res. 2007, 112. [CrossRef]

18. Fan, J.; Zhang, R.; Li, G.; Tao, W. Effects of aerosols and relative humidity on cumulus clouds. J. Geophys. Res. 2007, 112. [CrossRef]

19. Stevens, B.; Feingold, G. Untangling aerosol effects on clouds and precipitation in a buffered system. Nature 2009, 461, 607-613. [CrossRef] [PubMed]

20. Carrió, G.G.; Cotton, W.R. On the buffering of CCN impacts on wintertime orographic clouds: An idealized examination. Atmos. Res. 2014, 137, 136-144. [CrossRef]

21. Morrison, H.; Curry, J.A.; Khvorostyanov, V.I. A new double-moment microphysics scheme for application in cloud and climate models. Part 1: Description. J. Atmos. Sci. 2005, 62, 1665-1677. [CrossRef]

22. Morrison, H.; Gettelman, A. A new two-moment bulk strati-form cloud microphysics scheme in the Community Atmosphere Model, version 3 (CAM3), Part I: Description and numerical tests. J. Climate 2008, 21, 3642-3659. [CrossRef]

23. Mansell, E.R.; MacGorman, D.R.; Ziegler, C.L.; Straka, J.M. Charge structure and lightning sensitivity in a simulated multicell thunderstorm. J. Geophys. Res. 2005, 110, 1545-1555. [CrossRef]

24. Marshall, T.C.; MacCarthy, M.P.; Rust, W.D. Electric field magnitudes and lightning initiation in thunderstorms. J. Geophys. Res. 1995, 100, 7097-7103. [CrossRef]

25. Weisman, M.L.; Klemp, J.B. The dependence of numerically simulated convective storms on vertical wind shear and buoyancy. Mon. Weather Rev. 1982, 110, 504-520. [CrossRef]

26. Chu, C.M.; Lin, Y.L. Effects of orography on the generation and propagation of mesoscale convective systems in a two-dimensional conditionally unstable flow. J. Atmos. Sci. 2000, 57, 3817-3837. [CrossRef]

27. Gilmore, M.S.; Straka, J.M.; Rasmussen, E.N. Precipitation and evolution sensitivity in simulated deep convective storms: Comparisons between liquid-only and simple ice and liquid phase microphysics. Mon. Weather Rea. 2004, 132, 1897-1916. [CrossRef]

28. Mansell, E.R.; MacGorman, D.R.; Ziegler, C.L.; Straka, J.M. Simulated three-dimensional branched lightning in a numerical thunderstorm model. J. Geophys. Res. 2002, 107. [CrossRef]

29. Morrison, H.; Thompson, G.; Tatarskii, V. Impact of cloud microphysics on the development of trailing stratiform precipitation in a simulated squall line: Comparison of one- and two-moment schemes. Mon. Wea. Rea. 2009, 137, 991-1007. [CrossRef]

30. Seifert, A.; Beheng, K.D. A two-moment cloud microphysics parameterization for mixed- phase clouds. Part 2: Maritime vs. continental deep convective storms. Meteor. Atmos. Phys. 2006, 92, 67-82. [CrossRef]

31. MacGorman, D.R.; Cohen, A.; Mansell, T.; Ziegler, C. Flash rate, electrical, microphysical, and dynamical relationships across a simulated storm spectrum. In Proceedings of the 2008 AGU Fall Meeting, San Francisco, CA, USA, 15-19 December 2008.

32. Wiens, K.C. Summary of Colorado State University's LMA-Related Observations from STEPS. In Proceedings of the 2008 AGU Fall Meeting, San Francisco, CA, USA, 15-19 December 2008.

33. Yair, Y.; Lynn, B.; Price, C.; Kotroni, V.; Lagouvardos, K.; Morin, E.; Mugnai, A.; Llasat, M.C. Predicting lightning density in Mediterranean storms based on the WRF model dynamic and microphysical fields. J. Geophys. Res. 2010, 115, D04025. [CrossRef] 
34. Saunders, C.P.R.; Peck, S.L. Laboratory studies of the influence of the rime accretion rate on charge transfer during crystal/graupel collisions. J. Geophys. Res. 1998, 103, 13949-13956. [CrossRef]

35. Miller, K.; Gadian, A.; Saunders, C.P.R.; Latham, J.; Christian, H. Modelling and observations of thundercloud electrification and lightning. Atmos. Res. 2001, 58, 89-115. [CrossRef]

36. Andreae, M.O.; Rosenfeld, D.; Artaxo, P.; Costa, A.A.; Frank, G.P.; Longo, K.M.; Silva-Dias, M.A.F. Smoking rain clouds over the Amazon. Science 2004, 303, 1337-1342. [CrossRef] [PubMed]

37. Wang, C. A modeling study of the response of tropical deep convection to the increase of cloud condensation nuclei concentration: 1. Dynamics and microphysics. J. Geophys. Res. 2005, 110. [CrossRef]

38. Khain, A.; Rosenfeld, D.; Pokrovsky, J. Aerosol impact on the dynamics and microphysics of deep convective clouds. Q. J. R. Meteorol. Soc. 2005, 131, 2639-2663. [CrossRef]

39. Koren, I.; Kaufman, Y.J.; Rosenfeld, D.; Remer, L.A. Aerosol invigoration and restructuring of Atlantic convective clouds. Geophys. Res. Lett. 2005, 32. [CrossRef]

40. Van Den Heever, S.C.; Carrio, G.G.; Cotton, W.R.; DeMott, P.J.; Prenni, A.J. Impacts of nucleating aerosol on Florida storms. Part I: Mesoscale simulations. J. Atmos. Sci. 2006, 63, 1752-1775. [CrossRef]

41. Lin, J.C.; Matsui, T.; Pielke, S.R.A.; Kummerow, C. Effects of biomass-burning-derived aerosols on precipitation and clouds in the Amazon Basin: A satellite-based empirical study. J. Geophys. Res. 2006, 111. [CrossRef]

42. Chen, J.; Yin, Y.; Xiao, H.; Chen, Q. A numerical investigation of the impacts of anthropogenic sulfate aerosol on regional climate in East Asia. Asia-Pac. J. Atmos. Sci. 2014, 50, 391-403. [CrossRef]

43. Xiao, H.; Yin, Y.; Chen, Q.; Zhao, P. Impact of aerosol and freezing level on orographic clouds: A sensitivity study. Atmos. Res. 2016, 176, 19-25. [CrossRef]

44. Xiao, H.; Yin, Y.; Jin, L.; Chen, Q.; Chen, J. Simulation of the effects of aerosol on mixed-phase orographic clouds using the WRF model with a detailed bin microphysics scheme. J. Geophys. Res. 2015, 120, 8345-8358. [CrossRef]

45. Tao, W.; Chen, J.; Li, Z.; Wang, C.; Zhang, C. Impact of aerosols on convective clouds and precipitation. Rev. Geophys. 2012, 50. [CrossRef]

(C) 2016 by the authors; licensee MDPI, Basel, Switzerland. This article is an open access article distributed under the terms and conditions of the Creative Commons Attribution (CC-BY) license (http://creativecommons.org/licenses/by/4.0/). 